American Journal of Clinical and Experimental Medicine
2015;3(1-1): 7-13
Published online February 14, 2015 (http://www.sciencepublishinggroup.com/j/ajcem)
doi: $10.11648 /$ jajcem.s.2015030101.12
ISSN: 2330-8125 (Print); ISSN: 2330-8133 (Online)

\title{
Considering a public health model for control and prevention of emerging infectious diseases in Sub-Saharan Africa
}

\author{
Kenneth Anchang Yongabi \\ Tropical Infectious Diseases and Public Health Engineering Research group (TIDPHEng), Department of Public health, School of Health and \\ Medical Sciences, Catholic University of Cameroon, Bamenda, Cameroon
}

\author{
Email address: \\ yongabika@yahoo.com (K. A. Yongabi)
}

\section{To cite this article:}

Kenneth Anchang Yongabi. Considering a Public Health Model for Control and Prevention of Emerging Infectious Diseases in Sub-Saharan Africa. American Journal of Clinical and Experimental Medicine. Special Issue: Clinical Innovations, Developments in the Diagnosis, Management and Prevention of Ebola Disease (Marburg fever) and Hemorrhagic Fevers. Vol. 3, No. 1-1, 2015, pp. 7-13.

doi: $10.11648 /$ j.ajcem.s.2015030101.12

\begin{abstract}
Despite increasing global efforts to contain infectious diseases such as Ebola, HIV, and new strains of Hepatitis Virus, the spread and burden still constitute more than $25 \%$ of the global disease picture. In this report, insights on an innovative cost saving evolutionary learning laboratory model (ELS Lab) consisting of a systems approach to the control of infectious diseases are discussed. There have been many science-based analyses from demographic, epidemiologic, disease intervention, and economic control measures in Sub-Saharan Africa to curb infectious diseases, yet the continued spread of new and old infectious diseases poses a serious challenge to public health in SSA. There is persistent typhoid endermicity with emergence of new antibiotic resistant strains of salmonella typhi as well as non typhoidal salmonellosis. There is increasing resistant strains of Entameoba histolytica to metronidazle, poor response of patients to artemisinin based antimalarials and sporadic cholera is spreading. Although disease elimination programs such as against trypanosomiasis (chagas disease), onchocerciasis, lymphatic filariasis, leprosy, trachoma, and measles are succeeding such as drancontiasis elimination process is very successful in northern Nigeria and Cameroon, ebola virus disease, dengue, leishmaniasis, african trypanosomiasis, malaria, diarrheal diseases, helminthes infections, and tuberculosis are re-emerging due to inadequate interventions and control strategies couple with breakdown of health delivery systems. In most countries in SSA, the prevalence of HIV/AIDS is not less than $4 \%$ of the total population. The challenges caused by both new and old opportunistic infections in HIV/AIDS couple with increasing resistance to highly active antiretroviral therapy (HAART) calls for serious new intervention strategy. Endemic poverty and increasing changes in climatic pattern in the current control efforts especially with ebola virus are potentially playing a role in the persistence of these infections. We note that application of technologies must be culture driven, costeffective with intensified research is essential if these and other scourges are to be controlled or eliminated in the 21 st century. The process of ELS Lab involves all relevant stakeholders from rural and peri- urban setting, from end users of new medical technology innovations and indigenous management strategies to the developers of the technologies and policy awareness on the integration of safe and productive farm practices with less vulnerability to infections. We propose further capacity building and research into this model.
\end{abstract}

Keywords: Public Health, Model, Infections, Diseases, Systems Approach, Intervention

\section{Introduction}

Approximately $80 \%$ of all hospital admissions in SSA are due to infectious diseases. Infectious diseases are responsible for a high morbidity and mortality especially amongst children, and they account for one-fourth of the global burden of disease. The World Health Organization spends a quarter of its budget on intervention efforts to curb spread of infectious diseases. Despite the introduction of new tools for diagnosis, patient treatment, and vector control, the incidence and prevalence of malaria, salmonellosis,lymphatic filariasis, dracunculiasis, onchocerciasis, trachoma, chagas disease, and leprosy has decreased nonetheless, but the emergence of 
antibiotic resistant strains with increased burden and underlying poverty remains a daunting challenge. The impact of the infectious diseases on the African continent and some countries in Asia can be seen from the declining levels of disability adjusted life years (DALYs).A Number of factors may be contributing to the persistence of infectious diseases: declining health infrastructure, inability to pay for prescription drugs and poor environmental sanitation (Table 1)

Table 1. Global Infectious Disease burden expressed in DALYs.

\begin{tabular}{lllll}
\hline \multirow{2}{*}{ Region } & DALYS & & \\
\cline { 2 - 5 } & $\begin{array}{l}\text { population in Thousand } \\
(\%) \mathbf{a}\end{array}$ & $\begin{array}{l}\text { for all diseases } \mathbf{N}^{\mathbf{0}} \text { in } \\
\text { thousand (\%)b }\end{array}$ & $\begin{array}{l}\text { for infectious and parasitic } \\
\text { diseases } \mathbf{N}^{\mathbf{0}} \text { in thousand (\%)b }\end{array}$ & $\begin{array}{l}\text { for infectious and parasitic } \\
\text { diseases(\%) c }\end{array}$ \\
\hline Africa & $655,476(10.7)$ & $357,884(24.4)$ & $189,047(55)$ & 53 \\
South East Asia & $1,559,810(25.5)$ & $418,844(28.5)$ & $93,995(22)$ & 26 \\
Eastern Mediterranean & $493,091(81)$ & $136,221(9.3)$ & $34,741(26)$ & 10 \\
Western pacific & $1,701,689(27.8)$ & $257,868(176)$ & $23,163(9)$ & 3 \\
The Americas & $837,178(137)$ & $145,217(9.9)$ & $12,555(9)$ & 2 \\
Europe & $874,178(14.3)$ & $151,223(10.3)$ & $5,876(4)$ & 100 \\
Total worldwide & $6,122,210(100)$ & $1,467,257(100)$ & $359,377(24)$ & 6 \\
\hline
\end{tabular}

Note: Adapted: Infections of the lower and upper respiratory tract and otitis media pertusis, poliomyelitis, diphtheria, tetanus, meningitis, Hepatitis B and C are included in the date. DALYs, disability adjusted life years

(a) Percentage of total worldwide population

(b) Percentage of total worldwide DALYs for all diseases

(c) Percentage of total worldwide DALYs for all infectious and Parasitic diseases

Estimates using disability-adjusted life years (DALYs, an aggregate measure of premature mortality, morbidity and disability) show that several types of infectious diarrhea and the soil-transmitted helminthes infections (e.g., hookworm) outrank many of the infections in the Tropical disease Research portfolio. The United Nations Development Programme/World Bank/WHO Special Programme for Research and Training in Tropical Disease Research (TDR) was created in 1975 to develop improved and new diseasecontrol tools for 10 diseases and to strengthen the research capabilities of affected countries. TDR promotes use-inspired basic (and applied) research and cost-effective interventions for the control of neglected diseases indicates that almost all of the individual infectious and parasitic disease burden falls most heavily on Africa, Southeast Asia, the eastern Mediterranean, and the western Pacific (as those regions are defined by the WHO). Recent research advances include the successful testing of artemisinin-based drug combinations for treating malaria, the registration of oral miltefosine for treating visceral leishmaniasis, the use of prepackaged antimalarial drugs, and the development of evidence-based guidelines intended to eliminate lymphatic filariasis using drug combinations. There is great optimism for development of newer antimalarials and vaccines that use the recently sequenced genomes of major tropical pathogens and their vectors. The efforts and strides made by TDR are commendable, yet infectious disease burden still remain a great challenge to poorer nations as seen in table 2 below.

Table 2. Disparity in Infectious disease prevalence in rich and poor nations.

\begin{tabular}{|c|c|c|c|c|c|c|c|}
\hline \multirow[b]{2}{*}{ Disease } & \multicolumn{7}{|l|}{ Disease burden by region $\% b$} \\
\hline & $\begin{array}{l}\text { Disease burden worldwide } \\
\text { ALYs in thousands (\%) }\end{array}$ & Africa & $\begin{array}{l}\text { South East } \\
\text { Asia }\end{array}$ & $\begin{array}{l}\text { East } \\
\text { Mediterranean }\end{array}$ & $\begin{array}{l}\text { West } \\
\text { pacific }\end{array}$ & The Americas & Europe \\
\hline HIV/AIDS & $88,429(6.0)$ & 65 & 15.4 & 1.9 & 2.2 & 3.1 & 1 \\
\hline Diarrheal Diseases & $65,451(4.3)$ & 32.9 & 34.2 & 16.5 & 6.3 & 4.3 & 1.3 \\
\hline Malaria & $42,280(2.9)$ & 85.2 & 8.7 & 4.8 & 1 & 0.3 & 0.1 \\
\hline Measles & $26,495(1.8)$ & 57.1 & 26.1 & 11.5 & 4.4 & 0 & 0.9 \\
\hline $\begin{array}{l}\text { Sexually Transmitted } \\
\text { Diseases (c) }\end{array}$ & $12,404(0.8)$ & 41.4 & 34.8 & 10.7 & 5.1 & 5.1 & 2.9 \\
\hline Lymphatic filariasis & $5,644(.04)$ & 34.2 & 49.6 & 8.7 & 7.2 & 0.2 & 0.03 \\
\hline Trachoma & $3,997(0.3)$ & 38.2 & 6.2 & 15.1 & 40.6 & 0 & 0 \\
\hline Leishmaniasis & $2,357(0.2)$ & 17 & 67.3 & 11.8 & 1.1 & 2.5 & 0.3 \\
\hline Schitosomiasis & $1,760(0.1)$ & 80.6 & 0.2 & 11.5 & 2.9 & 10.4 & 0 \\
\hline Trichuriasis & $1,649(0.1)$ & 7.5 & 26 & 2.2 & 46.6 & 17.7 & 0 \\
\hline
\end{tabular}




\begin{tabular}{llllllll}
\hline \multirow{2}{*}{ Disease } & \multicolumn{2}{l}{ Disease burden by region \%b } & & & \\
& $\begin{array}{l}\text { Disease burden worldwide } \\
\text { ALYs in thousands (\%) }\end{array}$ & Africa & $\begin{array}{l}\text { South East } \\
\text { Asia }\end{array}$ & $\begin{array}{l}\text { East } \\
\text { Mediterranean }\end{array}$ & $\begin{array}{l}\text { West } \\
\text { pacific }\end{array}$ & The Americas & Europe \\
\hline $\begin{array}{l}\text { Afriican - } \\
\text { Trypanosomiasis }\end{array}$ & $1,598(0.1)$ & 97.4 & 0 & 2.5 & 0 & 0 & 0 \\
Ascariasis(d) & $1,181(0.1)$ & 10.2 & 22.8 & 5.2 & 46.4 & 14.6 & 0.7 \\
Onchoceriasis & $987(0.1)$ & 95 & 0 & 4.7 & 0 & 0.3 & 0 \\
Japanese -encephalitis & $767(0.1)$ & 0 & 45.2 & 10.6 & 44.3 & 0 & 0 \\
Dengue & $653(0.0)$ & 0.9 & 55.1 & 13 & 17.2 & 13.8 & 0 \\
Chaga's Disease & $649(0.0)$ & 0 & 0 & 0 & 0 & 99.8 & 0 \\
Leprosy & $177(0.0)$ & 9 & 67.2 & 9 & 4 & 10.2 & 0 \\
$\begin{array}{l}\text { All infectious and } \\
\text { parasitic diseases }\end{array}$ & $359,377(24.5)$ & 52.6 & 26.2 & 9.7 & 6.4 & 3.5 \\
\hline
\end{tabular}

Note: Adapted: Infections of the lower and upper respiratory tract and otitis media pertusis, poliomyelitis, diphtheria, tetanus, meningitis, Hepatitis B and C are not included in the date. DALYs, disability adjusted life years

(a) Percentage of total worldwide DALYs for all diseases

(b) Percentage of total worldwide DALYs for special diseases

(c) includes Syphilis, Chlamydia, and Gonorrhea

(d) intestinal nematode infection

Seven to eighty percent of the people in Africa and developing countries in general, live in the rural areas and practice subsistence farming. They are generally poor and lack basic amenities and infrastructure. They play host to a lot of diseases: Malaria, Typhoid, Skin diseases etc, and due to the high cost of drugs and inaccessibility to urban areas to purchase these drugs (when money is available); they resort to the use of indigenous plants and traditional medicine. The exploitation of this indigenous knowledge, especially medicinal plant resource base, and its enhancement for easy usage by our rural populace is viable tool in reducing the health problems raging our rural communities.

The African environment in particular is probably the least explored in terms of available resources. One needs to take a course to worlds' indigenous cultures and knowledge to discover untapped resources. Medicinal plants, vast indigenous knowledge and herbal medicines is readily available in our diverse vegetation, cheap and above all carries the potentials of introducing new templates into modern medicine. Indigenous knowledge and Medicinal plants have a long history of use in most communities throughout the world. To this effect, approximately, $80 \%$ of Africans depend on homeopathic medicine and other forms of indigenous knowledge for survival. In Africa, people still consult traditional healers even when being attended to in conventional orthodox clinics. The history of medicinal plants and traditional knowledge is widely documented in various pharmacopoeias; Planta medica, Napralert, e tc, around the world. Unfortunately, little effort in transforming these vast knowledge using simple low cost technology models are still farfetched. Apparently, a lot of rich unclassified indigenous knowledge on the therapeutic ability of medicinal plants abounds in Africa that has not been documented for possible modification and application by the academia to address the pressing problems of indigenous people on the African continent. There is no globalhealth model that incorporate indigenous knowledge base and traditional medicine in the control and prevention of diseases Historically, medicinal plants have provided a source of inspiration for novel drug compounds, eg Quinine the oldest antimalarial drug was inspired from a south American plant, Cinchonna tree bark, Vincristine and Vinblastine, the famous and widely used antileukaemia alkaloid drug was derived from Rose perinwinkle (Vinca rosea),Ergot Fungus (clavicep purpurea), Artemisia annua and a host of others are medicinal plants widely known to have inspired synthesis drugs used in modern medicines today .The use of plants in Medicine predates orthodox medical practice. For instance, the ayuverde practice of India is a medical system more than 3000years old (Singh,1986)Similar Traditional medical systems of china had been documented in China 2730 years ago by Shen Nuny. Plant derived medicines have large contributions to human health. It can be recalled that as far back as 1660, Napoleon Bonaparte used ipecacuanha, Kurchi- bark to treat amoebic dysentery and other complications of amoebiasis. Many of Such examples of indigenous knowledge and practices abound throughout the world and remain largely underutilized through appropriate technology. There are increased use of herbal products globally,for instance ,between 1990 and 1997,the use of herbal based products reached 38\% (Elsenberg et al,1990) The World Health Organization(WHO) has estimated that up to $80 \%$ of the world's population rely on plants for their primary health care while in Nigeria, WHO surveys in 1985 estimated that up to $75 \%$ of the population patronize traditional medicine(Omoseyindemi,2003)

\section{Establishing Systems thinking and evolutionary Learning laboratories for infectious disease control and eradication}

In a preliminary pilot study we undertook in Boyo division 
in North West Cameroon, Stakeholders at all levels were made to work together through a participatory approach and capacity building to define appropriate solutions hinged on both orthodox and traditional knowledge resources, propose and package practical and applicable community based strategies in different cultural, economic, political, social and environmental context. Capacity building on skills transfers of the package technologies on household nutritional support and immune boosters for malaria and other emerging infections like Ebola control from indigenous food plants and mushrooms, as well as indigenous ornamental plants that repel mosquitoes, potentially control vectors of other emerging infections were considered and discussed. Decontamination of noxious causing pathogens from animal wastes with potential value addition for use in sustainable agriculture was exciting. The case of the use of anaerobic digesters and fermenters to disinfect hospital wastes discharges that potentially generate mineralized slurry for agricultural use was illustrated as a group with each member suggestion ideas toward how the community can get well involved. Four training modules on mentality change and growing positive health schemes were conducted amongst 78 rural community based groups. The results suggested a decline in the prevalence of malaria and other infectious could be seen in the months ahead. It was also believed by the participants that this could be the approach in the threat of Ebola in Cameroon. Furthermore, a high re-awakening of the application of indigenous knowledge in the treatment and management of typhoid fever, malaria and possibly ebola for improved immunity of the community members were practically discussed in the group sessions. The conclusions derived at by the members themselves is the possibility of less visits to the local hospitals as well as an increased community engagement in disease control.

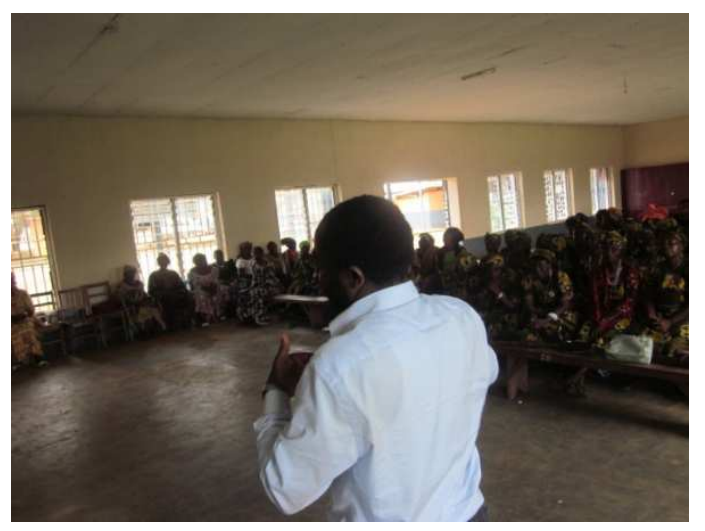

A community learning and knowledge sharing Lab for Ebola and on other Infectious literacy held in Kom, North West Cameroon August 2014.

Why such a Systems thinking approach in Disease control is important.

The largely linear and mechanistic approaches used in the past centuries to resolve medical problems are proving inadequate to solve contemporary health problems. This is seen in the current efforts to control ebola in West Africa.
Systems are fundamental to the organization and functioning of the world and ecosystems, and the interdependence of system variables is well established. They naturally interact with one another so eloquently such that cause and effect remain linked. It has been customary that over the years in medical sciences, and in many other fields and disciplines, we therefore have been building treatments and interventions without a systems approach. We therefore make decisions with systemic impacts. These can be latent innocent accidents, like inadvertently clicking in ones'- mail box reply to all as described by Bosch et al (2013). Or deliberate choices, like refusing to go to the hospital rather than take medication at home. In this scenario, both actions will, ultimately, affect the systems in which they occur, although one could have made the decision without any thought of the existence of the much larger systems of which our actions are part of.

The insidious consequence of non-systemic decisions or solutions to health problems in the world, such as introducing a single chloroquine molecule taken out from a library of synergistic willow bark extract just to be faced with plasmodium falciparium resistance in the next decade is an unsystemic decision. In the case of Ebola, introducing Zmapp against the virus is a temporal solution. Or a medical system that fails to see that food security is intrinsically linked to improve health in the face of emerging disease threat is the increased need for the continued introduction of more and more 'solutions' because no decision that was made or is being made, considered the impact of the solution on the entire 'health system', 'health poverty' and 'health resources' of the people in SSA, as a whole or vice versa.

This phenomenon probably explains why many NGOs across Africa and hospital managements, and governments intervention strategies, although with best intentions grossly remain ineffective and inadequate to solve the infectious diseases debacle but are now 'addictive'. They foster increased dependency on treatment and stereotype interventions and lessen the ability of the local people to solve their own health problems. A clear case is seen in the countries worst hit by Ebola; the community is helpless and depends on foreign support. This may not have been the case if a community learning health care scheme exist with the people and with the hospital that can address any new disease threat and not just with ebola. In circumstances where beneficial health intervention changes are desired in systems, for example, giving for free insecticide bed treated nets, and the free administration of pyrimethamine/Suphodoxine tablets to pregnant women in SSA attending antenatal follow up, actions are required that foster awareness among the local stakeholders of the systemic nature of the social and natural systems that are endowed to each community, that can be tapped to eradicate or drastically sustain the reduction of the malarial burden. Experiments and capacity buildings in systems thinking and associated evolutionary learning are stimulating interest and changing perceptions and behavioral changes amongst our social local groups in Cameroon with possible expansion in our test co-learning groups in Uganda, and Ghana etc The same holds for medical students and 
women groups in Cameroon, that promise to not just change individual lives, but to change the worlds' perceptions. As a system approach to understanding and solving the persistent endemic infectious disease problem, systems thinking, and its learning branches, represent interaction with communities, their local chiefs, conversation with the local people of each tribes in SSA and awakening their indigenous knowledge on intervention, then the acquisition of new habits of thought and action based on a fundamental reality that they experience which is commonly ignored: cause and effect are not linear.

\section{Paradigm shift for Stakeholders in Health Care in Africa}

The medical practitioners, scientists and NGOs involve in the control of infectious disease such as malaria, typhoid and cholera and ebola fight would need to know that thinking and action evolve, not in a straight line, not a medical demagogy, but in spirals, circles and webs. For instance, we can give a free mosquito bed net to prevent a mosquito bite at home but can be bitten by a mosquito in the evening while a woman is cooking or in an office or as they go to their farms. She definitely will not carry a mosquito bed net to the farm. Pregnant women can be given a pill of fansidar to swallow during antenatal follow up but her poor diet due to poverty could provoke the resurgence of sub clinical plasmodiasis (merozoites) to multiply, get to the peripheral blood and cause bouts of fever without a fresh mosquito bite. Giving a free mosquito bed net without an appropriate technology that addresses cultural habits, clean water and safe sanitation at home and possible incorporation of indigenous knowledge and indigenous medical practices can be very universally disappointing because of the failure to acknowledge the underlying systems of poverty and its interwoven causes, lack of holistic education and appropriate technologies hinged on the strengths and weaknesses of the people, their tribe and cultural inclinations, each community with the right institutional support.

This systems thinking approach to the control of infectious diseases we are advocating here underpins on the mental, cultural, indigenous knowledge resources, indigenous medicine that would generate nutriceuticals from their local flora and fauna that boosts immunity of the people living in a community and traditional environmental sanitation methods that controls mosquitoes, use of plastic digesters to process animal and home wastes to produce sterile slurry that repels mosquitoes as well as cultural and traditional institutional support and government institutional support. This fundamentally means that hospitals in Africa would have to be restructured to reflect the western approach and African approach to health care provision if it is to succeed in improving health care for her people. The Systems Learning laboratory (ELS Lab) is a super innovative, super interactive with health literacy, individual patients health rights at the core, a unique and creative process in which a diverse group of people in a community including children and the elderly, medics, tradimedical practitioners, engage in a cyclical process of learning together in an 'experimental perceptional laboratory' to understand why certain infectious diseases such as malaria, typhoid and ebola would persists in each community with respect to that community setting and address its complex multidimensional and multi-stakeholders challenges in a systemic and systematic way. This laboratory doesn't refer to a tangible physical space per se, but a place in the minds of the community participants to understand their cultural habits, "old-new" indigenous knowledge base that can prevent and treat infections, and uptake of a package of holistic appropriate technologies hinged on this local knowledge for uptake at community levels.

The ultimate goal is to achieve sustainable outcomes for global infectious disease control in children, elderly and the entire communities in SSA countries through the interaction of all the system variables: For example, the entire community playing and implementing a community based malarial control scheme built on local knowledge, use of nutriceuticals/ dietary supplement from indigenous plants and foods to boost immunity of children, the government's role, the district medical centres and officers' roles. Besides, donors perception in supporting systems built intervention strategies for example malaria, typhoid, diarrhea and malnutrition, food and fuel suppliers, designers, the local chiefs, whoever and whatever is in the system since all variables are critical to the success of this intervention approach.

\section{Examples of Systems Thinking Approach in Non Medical Disciplines}

The systems thinking and the concept of Learning laboratories is being studied more and more in our pilot project communities in Cameroon with possible extension to Ghana and Uganda, Ethiopia and needs to be well strengthened and widely promoted at the global health institutes around the world. The feasibility and sustainability is unequivocal. The outcome of this model in non health pilots can be seen in the ZERI program for sustainable food and environment by Gunter Pauli of the ZERI foundation (www.zeri.org), growing power in Milwaukee in the Wisconsin state in the USA (www.growingpower.org) and in the Songhai project in Porto novo, in Benin republic, and our pilot experimental ELS Lab in Cameroon at www.phytobiotechcameroon.org, an institute of the Catholic University of Cameroon, Bamenda.

It is believed that this could be the first eco health villagemodel across Africa to contain endemics and pandemics like ebola built on a systems laboratory in the world to control infectious diseases. When the guidelines for our design of new innovative health care package for sustained control of infections in SSA have been generated and an appropriate implementation plan developed which summaries of the first part of our work, our research consortium will further on 
with building up systems package by collating the final step of the ongoing integrated cyclic and holistic process. A summary of the procedures for setting an ElLab we designed were as follows: systematically defined strategies that we have evolved, the cultured driven and perception driven technologies reminiscent of the African cultures, tools and policy briefs addressing the root causes of the endermicity of certain infectious diseases such as malaria around, boosting cost efficient interventions were implemented and is under study at community levels within the context of the learning laboratory- meaning learning and growing with the knowledge by doing.

A final meditation and contemplative stage was generated. At this stage the researchers and all stake holders were allowed to independently and as a community judge and determine how successful or unsuccessful the model intervention has been and as such to identify unforeseen consequences and maybe new barriers that were previously not seen. We think that by this interactive process in community, the management of infectious diseases could inspire change and may serve as a valuable informal colearning and doing together experience, leading to new levels of capabilities hidden amongst our indigenous people and all stakeholders and improving performance by both end users and those designing and providing new health care technologies, tools and management strategies.

In the case our pilot, as soon as the ELS Lab for infectious disease control was established and institutionalized attempts were made to operate as a management tool in our next phase of work. Further fine tuning were made by incorporating potential appropriate technologies and tools for cost saving and benefits of malarial and typhoid interventions in kom village in Cameroon. This village is being used to test this model.

Continuous identification of impacts barriers and successes are being made which involved identifying the barriers, and making a strong implementation plan. The systems lab for malarial and typhoid and Ebola control- the three diseases we are paying particular attention through an opinion pool and structured questionnaire to further built a community and culturally driven intervention package. Further steps in the effective development of this model are proposed and recommended to the World Health Organization and centre for diseases control.

\section{References}

[1] K.A. Yongabi (2003) A technical Report Report on a capacity building training of rural women in some selected Communities of Bauchi State on Soap (Washing) Production. A technical Report submitted to Development Exchange Centre (DEC), Bauchi office, March 17, 2003, FEPA/ZERI CENTRE, ATBU BAUCHI.

[2] Bosch, O. J. H., Nguyen, N. C., Maeno, T., \& Yasui, T. (2013). Managing Complex Issues through Evolutionary Learning Laboratories. Systems Research and Behavioral Science, 30 (2), pp 116-135
[3] Bosch, O. J. H., Nguyen, N. C., \& Sun, D. (2013). Addressing the critical need for a "new way of thinking" in dealing with complex issues facing our societies (Best Paper Award). Business Systems Review, 2 (2), pp 48-70 (Special Issue Selected papers of the first B.S.Lab International Symposium).

[4] Yongabi, K.A; Yusuf, I.Z; dongs, I.S.andAnong, D.S. (2004) Prevalence of Filariasis and Some Traditional methods of attending to the disease in Wum, North West of Cameroon. Nigerian Journal of Microbiology, Vol.18, No.1-2 ISSN07941293, PP207-211

[5] K.A.Yongabi (2004) Medicinal plant biotechnology:It's Role and Link in Integrated (The Role Of Medicinal plants in Environmental biotechnology and integrated biosystems Biosystems.) Proceedings of an International E -Seminar organized by the International Organization for Biotechnology and Bioengineering (IOBB), WebPage: www.biotech.kth.se/iobb/activities.(www.iobbnet.org,www.io bbnet.mpb.doc,March 8-22,2005.

[6] K.A.Yongabi; M.O.Agho; A.L.Abdullahi and O.J.Abayeh (2005) An Integrated Bio-systems for Agricultural Wastes Management in Bauchi-Nigeria through Mushroom cultivation. Journal of League of Researchers in Nigeria (JOLORN) Vol.5, No.2, pp76to 81.

[7] Yongabi, K. A. (2005) Development of a Pilot backyard farm at Kuru Jos, Plateau State CARUDEP, IBS project. Proceedings of an Internet conference on Phytoremediation and water purification, International Organisation of Biotechnology and Bio engineering http://www.iobbnet.org/iccb-africa/bbua

[8] K.A Yongabi(2007)Inventory of African Indigenous Knowledge in water treatment and Sanitation in Cameroon and Nigeria:A Preliminary study on the disinfection of fresh human Excrement with Medicinal plant extracts,Kerosene and Saw dust,Accepted for Presentation at the International Conference on Sustainable Sanitation/Eco cities and Villages,Dongsheng,Erdos,Inner Mongolia,China,August 26 to 29

[9] K.A.Yongabi, W.F.Mbacham, K.K.Nubia and R.M.Singh (2009) Yeast strains isolated from HIV-seropositive patients in Cameroon and their sensitivity to extracts of eight medicinal plants. African Journal of Microbiology Research,vol.3 (4),PP.133-136

[10] Yongabi,K.A,Lewis,D.M and Harris,P.L Indigenous plant based coagulants and sand filter media for surface water treatment in Bamenda,Cameroon. African Journal of

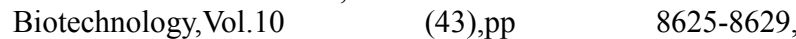
online.www.academicjournals.org/AJB

[11] Bob Orskov, Kenneth Yongabi,Madhu Subedi and Jo Smith (2013) Overview of holistic application of biogas for small scale farmers in Sub-Saharan Africa, Biomass and Bioenergy) www.sciencedirect.com/science/article/pii/S09619534140012 51

[12] Kenneth Yongabi, Lisa Avery and Ambar Pertiwiningrum (2013) A Commentary of Occupational Infectious Diseases due to Agricultural Practices in Sub- Saharan Africa, Biomass and Bioenergy www.sciencedirect.com/science/article/pii/S09619534140012 51 
[13] Yongabi Kenneth,Lewis David and Harris Paul (2010) Alternative Perspectives in water and wastewater treatment.(Blurb title:Phytocoagulant sand-filter and plastic anaerobic digesters for water and wastewater treatment.) Lambert Academic publishers, Germany. 127 pages, ISSBN 9783838387857)

[14] Kenneth Yongabi Anchang (2013) An Evolutionary Learning Pharmaceutical Laboratory For Cost Saving Eradication of Malaria in Sub- Saharan Africa through phytobiotechnology.OMICS Group,International Submit on Clinical Pharmacy and Dispensing, November 1820,2013,Hilton San Antonio Airport,TX, USA

[15] Uptake of Nutritional Supplementation from Spirulina Platensis and African Medicinal plants for the therapeutic management of HIV/AIDs patients in Cameroon Kenneth Yongabi.www.formatex.info/icar2012/abstracts/htm/198.pdf

[16] Kenneth Yongabi (2013)Invited lecture presented to the Department of Medical Microbiology and Immunology on: Disease burden in Sub-Saharan Africa: An Appraisal of Social, Cultural, and Economic and health policy implications on September 6, 2013 in the school of Medicine and Public Health, University of Wisconsin-Madison, USA.
[17] Kenneth Yongabi (2013)Invited Lecture presented to the Global Health Institute on: Can we conquer malaria: A Reassessment of Current Intervention Strategies and potential application of Phytomedicine and Nutraceuticals on September 12, 2013, University of Wisconsin- Madison,USA

[18] Kenneth Yongabi (2013) Invited Lecture presented to the Infectious Disease Doctors' group of School of Medicine and Public Health on: Typhoid and febrile Illness: An Endermic but an Emerging and Re-emerging Infectious Disease in SubSaharan Africa, University of Wisconsin- Madison, USA, September 27, 2013.

[19] Kenneth Yongabi (2013) Invited Lecture presented to the School of Veterinary Medicine and Public Health on: Occupational infectious diseases due to agricultural practices in Sub-Saharan Africa with Focus on emerging Zoonotic infections, University of Wisconsin-Madison, USA September 17,2013

[20] Kenneth Yongabi (2013) Invited Lecture Presented to the Department of Dermatology, School of Medical Sciences, and University of Wisconsin-Madison, USA on: Clinical Management of HIV/AIDS related skin Diseases in Cameroon with Bioactive Plant extracts. October 7, 2013 